\title{
The Diabetes-Prone NZO/HILt Strain. I. Immunophenotypic Comparison to the Related NZB/BINJ and NZW/LacJ Strains
}

\author{
Bradford D. Haskell, Kevin Flurkey, Theodore M. Duffy, Evelyn E. Sargent, and \\ Edward H. Leiter
}

The Jackson Laboratory, Bar Harbor, Maine

\begin{abstract}
SUMMARY: New Zealand Obese (NZO)/HILt male mice exhibit a polygenic obesity and approximately $50 \%$ develop type 2 diabetes. This strain is known to produce a variety of autoantibodies, including autoantibodies to the insulin receptor. Because of their relatedness to the autoimmune-predisposed New Zealand Black (NZB) and New Zealand White (NZW) inbred strains, we compared NZO to its two related strains for shared hematologic and immunologic characteristics. Comparison of the three strains by serotyping and genotyping methods indicated that NZO shared with NZW the rare (recombinant) $H 2^{z}$ haplotype at the major histocompatibility complex. Similar to the NZB and NZW strains, spleens from NZO mice contained increased numbers of $\mathrm{CD} 19^{+} \mathrm{CD}_{43}{ }^{+} \mathrm{IgM}^{+} \mathrm{B}-1 \mathrm{~B}$ cells, a phenotype associated with natural autoantibody production. NZO mice developed a progressive microcytic anemia that was distinguished from NZB hemolytic anemia by absence of demonstrable antierythrocyte antibodies in the former. Outcross of NZO females with NZB males accelerated development of obesity and diabetes in F1 males. NZO males made B-lymphocyte-deficient by a disrupted immunoglobulin heavy chain gene did not become diabetic. These results suggest that NZO mice should be useful to investigators interested in studying the genetic contributions to autoimmunity made by the related NZW and NZB strains. Further, these results, combined with the pancreatic histopathology contained in the companion manuscript, suggest that B lymphocytes may be important contributors to diabetes pathogenesis in the NZO mouse. (Lab Invest 2002, 82:833-842).
\end{abstract}

$T$ he New Zealand Obese (NZO) mouse is an inbred strain derived in New Zealand from outbred stock from the Imperial Cancer Research Fund Laboratories in London (Bielchowsky and Bielschowsky, 1956). This is the same outbred stock that gave rise to the autoimmune-predisposed New Zealand Black (NZB) and New Zealand White (NZW) inbred strains. The original selection for these three strains was for coat color; NZO progenitors were initially selected for agouti coat color and later for polygenic obesity (Herberg, 1988). NZO mice have been studied primarily as a mouse model of obesity-induced insulin resistance (Proietto and Larkins, 1993). Interestingly, transition from obesityinduced insulin resistance and impaired glucose tolerance to overt type 2 diabetes ("diabesity") appears to be a colony-dependent phenomenon, with mice of the NZO substrain in Australia (NZO/Wehi) currently showing little development of clinical disease (Thorburn et al, 2000), whereas $\mathrm{NZO} / \mathrm{HI}$ and NZO/HILt males develop diabetes at a frequency of $40 \%$ to $50 \%$ (Leiter et al, 1998). NZO/HI

\section{DOI: 10.1097/01.LAB.0000018915.53257.00}

Received January 14, 2002.

This study was initiated through NIH PO1-RR08911 from the National Center for Research Resources and is currently supported by NIH-56853 from NIDDK. Institutional shared services were supported by National Cancer Institute Cancer Center Support Grant CA-34196 to The Jackson Laboratory.

Address reprint requests to: Dr. Edward H. Leiter, The Jackson Laboratory, 600 Main Street, Bar Harbor, ME 04609. E-mail: ehl@jax.org females in Düsseldorf and NZO/HILt females in Bar Harbor develop marked obesity, but remain diabetesfree (Leiter et al, 1998). Because of the early development of obesity, the strain is difficult to breed and has not been widely studied. Thus, despite their relatedness to the autoimmune-prone NZB and NZW strains, only limited analysis of the immune system of NZO mice has been reported previously (Melez et al, 1980, 1985). These studies indicated that NZO shared some of the classic autoimmune abnormalities found in the NZB strain, and suggested that diabetes development might be associated with the autoimmunity. Among the immune anomalies reported were the development of lgM autoantibodies to native and single-stranded DNA as well as IgM immune complex deposition in kidney (Melez et al, 1980). Another immune anomaly shared with the NZB strain was splenic hypertrophy with increased basal splenocyte proliferation in vitro, but reduced mitogenstimulated proliferation. However, this hyperproliferative phenotype was reversed by insulin administration only in NZO, and not in NZB (Melez et al, 1985), suggesting that the immune anomaly in NZO was a consequence of the insulin resistance. That autoimmunity may contribute, in part, to the metabolic syndrome (obesity, insulin resistance, and hyperglycemia) in NZO mice was nevertheless suggested by the report that this strain spontaneously develops autoantibodies to the insulin receptor (Harrison and Itin, 1979). Because low-affinity natural autoantibodies are often produced by polyreactive, T-independent B-1 B lymphocytes (Stall et al, 1996), we 
compared this phenotype $\left(\mathrm{CD} 19^{+} \operatorname{IgM}^{+} \mathrm{CD} 43^{+}\right)$in NZO/ HILt with the two other NZ strains available at The Jackson Laboratory, NZB/BINJ and NZW/LacJ. We further characterize the MHC of NZO mice and find apparent identity with the $\mathrm{H}^{z}$ haplotype expressed by the autoimmune-prone NZW strain. The latter strain is wellknown for its contribution of susceptibility modifiers, including $\mathrm{MHC}$, capable of accelerating autoimmune lupus in (NZB $\times$ NZW) F1 hybrids (Wanstrat and Wakeland, 2001). Because the NZB genome synergizes with the related NZW genome to exacerbate lupus-like symptoms in F1 hybrids (Theofilopoulos and Kono, 1998), we were curious to see whether the NZB genome would interact comparably with the NZO "diabesity-prone" genome to accelerate or suppress the "diabesity" syndrome. Indeed, we show that the obesity and diabetes syndrome is exacerbated in $\mathrm{F} 1$ males produced from $\mathrm{NZO} \times$ NZB outcross, whereas B-lymphocyte-deficient $\mathrm{NZO}$ males failed to develop hyperglycemia.

\section{Results}

\section{MHC Haplotype Characterization}

On importation of the NZO/HI strain to The Jackson Laboratory, a genetic quality control analysis was performed that entailed screening peripheral blood leukocytes with a panel of mouse alloantisera against various major murine MHC haplotypes (Snell et al, 1971). The only alloantiserum binding to NZO leukocytes as detected by a complement-mediated microcytotoxicity assay was one produced against the $\mathrm{H}^{\mathrm{z}}$ of NZW mice (a $K^{u} D^{z}$ recombinant haplotype). To confirm that $\mathrm{NZO}$ was $\mathrm{H} 2$-identical to $\mathrm{NZW}$, a new CBA/J anti-NZO/HI alloserum (AS-961) was generated that reacted with both $\mathrm{NZO}$ and NZW leukocytes in a complement-mediated microcytotoxicity assay. An anti-H2-Ku alloantiserum also killed NZO leukocytes. Both alloantisera produced $100 \%$ lysis of NZO and NZW splenic leukocytes at a 1/64 dilution in microcytotoxicity assay. Further confirmation that $\mathrm{NZO}$ and NZW shared the $\mathrm{H}_{2}{ }^{\mathrm{z}}$ recombinant haplotype was obtained by typing intra-MHC polymorphic alleles using simple sequence repeat-based PCR (Table 1). D17Mit16 is a simple sequence repeat positioned just centromeric to $\mathrm{H} 2-\mathrm{K}$; NZO and NZW genomic DNA produced an identical PCR product (90 bp) that was distinct from that of either NZB (107 bp) or C57BL/6J (92 bp). Similarly, NZO and NZW DNA tested with primers for D17Mit 21, positioned in the MHC class II region, gave an identical product size (150 bp) that was again distinguished from that in NZB (165 bp) and B6 (137 bp). Primers for D17Mit103, positioned in the $\mathrm{MHC}$ class III region, also showed NZO/NZW product size identity (155 bp), distinguishable from NZB (165 bp) and B6 (103 bp). Using PCR primers based on the published promoter sequence of the NZW H2-Aa promoter region (Rozzo et al, 1999), we also confirmed an identical product size for NZO (150 bp, versus 120 bp for NZB). Lastly, a NZW-diagnostic microsatellite polymorphism in the TNF- $\alpha$ promoter (Fujimura et al, 1998) was found in NZW (both products were $100 \mathrm{bp}$ versus 95 bp in NZB and 110 bp in B6; Table 1). From these typings, we conclude that NZO indeed is $\mathrm{H}^{\mathrm{z}}$ identical to NZW for the multiple alleles typed and thus may be a useful control for certain immunogenetic studies in NZW.

\section{Comparison of Splenic Leukocyte Populations}

Table 2 provides comparative data for splenic leukocyte populations of 6-month-old NZO, NZB, and NZW male mice. Total splenic leukocyte counts were significantly higher in NZO compared with NZW, but not with NZB. Whereas mean numbers of NZO T cell subsets $\left(\mathrm{CD}^{+}\right.$and $\left.\mathrm{CD} 8^{+}\right)$did not differ statistically from the two related strains, total numbers of CD19 ${ }^{+}$ $\mathrm{B}$ lymphocytes were significantly higher in NZO males compared with both NZB and NZW males. Total numbers of splenic neutrophils $\left(\mathrm{Mac}^{+}, \mathrm{Gr}^{+}\right)$were also significantly increased in NZO males compared with NZB males. NZW males were not examined for splenic neutrophils and macrophages. However, these cell types were enumerated in a group of three NZW females. These female values (neutrophils, 3.20 $\pm 0.63 \times 10^{6}$; macrophages, $3.20 \pm 1.47 \times 10^{6}$ ) were not different from the values shown for NZB males in Table 2, but were significantly lower than those observed in age-matched NZO females (neutrophils, $8.40 \pm 0.70 \times 10^{6}$; macrophages, $8.30 \pm 1.90 \times 10^{6}$ ). NZO females did not differ significantly from agematched males in any of the leukocyte populations assessed (data not shown). In summary, spleens from

Table 1. PCR Analysis of NZO/HILt MHC Alleles ${ }^{a}$

\begin{tabular}{llrrrr}
\hline \multicolumn{1}{c}{ Locus } & $\begin{array}{c}\text { Position } \\
(\mathrm{cM})^{b}\end{array}$ & NZ0 & NZW & NZB & B6 \\
\hline D17Mit16 & 18.18 & 90 & 90 & 107 & 92 \\
D17Mit21 & 18.63 & 150 & 150 & 165 & 137 \\
Aa promoter & 18.64 & 150 & 150 & 120 & - \\
D17Mit103 & 18.7 & 155 & 155 & 165 & 103 \\
D17Mit83 & 18.9 & 120 & 120 & 125 & 134 \\
TNF $\alpha$ promoter & 19.05 & 100 & 100 & 95 & 110 \\
\hline
\end{tabular}

\footnotetext{
a Polymorphisms generated PCR fragment sizes (in base pairs, bp) determined by gel electrophoresis in calibrated, ethidium bromide-stained $4 \%$ Metaphor agarose gels.

${ }^{b}$ MIT microsatellite map locations from The Jackson Laboratory's Mouse Genome Database.

${ }^{c}$ Marker located just distal $(0.29 \mathrm{cM})$ to $H 2-K$.
} 
Table 2. Comparison of 6-Month-Old NZO, NZB, and NZW Male Splenic Leukocyte Mice Populations

\begin{tabular}{cccccrc}
\hline Strain $(n)$ & Total Cells & \multicolumn{1}{c}{$\mathrm{CD}^{+}$} & \multicolumn{1}{c}{$\mathrm{CD}^{+}$} & $\mathrm{CD}^{+} 9^{+}$ & $\mathrm{Mac1}^{+} / \mathrm{Gr}^{-c}$ & $\mathrm{Mac1}^{+} / \mathrm{Gr} 1^{+c}$ \\
\hline NZO/HILt (8) & $230.09^{a} \pm 32.08$ & $32.97 \pm 7.15$ & $10.90 \pm 0.91$ & $73.65^{b} \pm 10.70$ & $6.83 \pm 0.92$ & $7.80^{d} \pm 0.90$ \\
NZB/BInJ (6) & $151.90 \pm 26.70$ & $22.75 \pm 2.94$ & $10.10 \pm 1.72$ & $35.87 \pm 11.23$ & $3.750 \pm 0.85$ & $3.75 \pm 0.85$ \\
NZW/LacJ (6) & $125.33 \pm 16.80$ & $19.72 \pm 1.96$ & $8.82 \pm 0.99$ & $34.06 \pm 5.18$ & - & - \\
\hline
\end{tabular}

NZO, New Zealand Obese mice; NZB, New Zealand Brown mice; NZW, New Zealand White mice.

Data are mean cell number $\left(\times 10^{6}\right) \pm$ SEM $(n)$.

${ }^{a}$ NZO significantly different $(p<0.05)$ from NZW/LacJ only by ANOVA.

${ }^{b} \mathrm{NZO}$ significantly different $(p<0.05)$ from both NZB/BInJ and NZW/LacJ.

${ }^{c}$ Data represent one experiment with NZO/HILt $(n=3)$ and NZB/BInJ $(n=2)$.

${ }^{d}$ NZO significantly different $(p<0.05)$ from NZB/BInJ.

NZO males contained more leukocytes than either of the related NZB and NZW strains, with the significant differences limited to the B lymphocyte and granulocyte/macrophage populations. These findings obtained by flow cytometry were consistent with histology showing very large germinal centers in spleens from NZO males.

\section{NZO Spleens Contain Comparable Numbers of B-1 B Lymphocytes to Spleens from NZB and NZW}

Splenic B-1 B lymphocytes account for a high proportion of antibody secreting cells and are associated with production of "natural antibodies" as well as autoantibodies (Martin and Kearney, 2001). Because both NZB and NZW strains reportedly produce increased numbers of B-1 B lymphocytes (Hamano et al, 1998; Phillips et al, 1992), we compared the abundance of this subpopulation in NZB and NZW with that in NZO (Fig. 1). Data for B6 are included as representative of a strain that does not produce high levels of spontaneous autoantibodies. The criterion typically used for identifying this subset in spleen is coexpression of CD43 in combination with CD19 and surface $\operatorname{lgM}$ (slgM) (Stall et al, 1996). Among the $\operatorname{lgM}^{+}$splenic B lymphocytes (which include follicular [CD19+ ${ }^{+}$slgMdull $\mathrm{CD} 43^{-}$], marginal zone $\left[\mathrm{CD}_{19}{ }^{+} \mathrm{IgM}^{+} \mathrm{CD} 43^{-}\right]$, and B-1 B lymphocytes), higher numbers were observed in B6 $\left(54.9 \times 10^{6}\right)$ and NZO $\left(53.4 \times 10^{6}\right)$ compared with NZW $\left(34.1 \times 10^{6}\right)$ and NZB $\left(35 \times 10^{6}\right)$. However, most B6 splenic leukocytes were follicular and marginal zone cells, with almost 2-fold fewer $\mathrm{CD}_{4} 3^{+}$cells in $\mathrm{CD}^{1} 9^{+} \mathrm{IgM}^{+}$subpopulation compared with NZO mice (Fig. 1). Although NZO had higher mean total numbers of splenic B-1 B lymphocytes than the other three strains, only the difference between NZO and B6 attained statistical significance.

\section{Peritoneal Leukocyte Subsets in NZO Mice}

Historically, peritoneal B-1 B lymphocytes have been enumerated using a somewhat different set of phenotypic markers than the combination of CD19, slgM, and CD43 used to identify the same subset in spleen. Subsets of peritoneal B-1 B lymphocytes (called B-1a cells) have been identified on the basis of high expression of CD5, coexpressed with B220 in combination with high slgM expression but weak IgD expression (Hayakawa et al, 1984). CD5-negative B-1 B lympho-

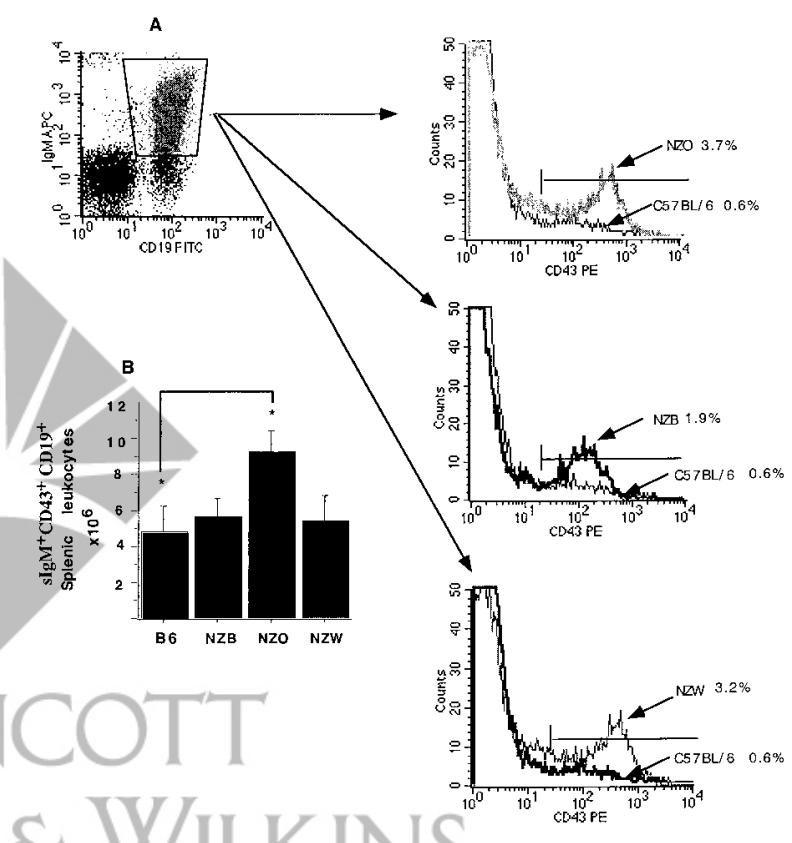

Figure 1.

Strain comparison of B-1 B lymphocytes in spleen of 3-month-old male mice by FACSCalibur cytometer. The upper-left panel shows the gated population of surface $\lg \mathrm{M}(\operatorname{slg} \mathrm{M})^{+} \mathrm{CD}^{+}{ }^{+} \mathrm{B}$ cells in New Zealand Obese (NZO), New Zealand White (NZW), and New Zealand Black (NZB) mice analyzed for expression of CD43 (right panels). The bar graphs show the numbers of

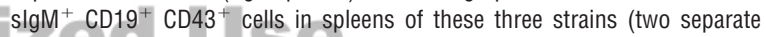
experiments, three to six males per strain), as well as the nonautoimmuneprone $\mathrm{C57BL} / 6 \mathrm{~J}$ (B6) strain. Only the difference between NZO and B6 means was significant at $p \leq 0.05$.

cytes (called B-1b cells) are present that also express high slgM and reduced IgD (Hayakawa and Hardy, 2000). CD5 expression is not a reliable marker for this subset in spleen because it is apparently downregulated during $\mathrm{B} 1-\mathrm{B}$ emigration from the peritoneal cavity to the spleen. One of the strain characteristics of NZB mice is a large population of leukocytes resident in the peritoneum. As shown in Table 3, a sampling of nucleated cells recoverable by peritoneal saline lavage from older NZO versus NZB mice of both sexes showed that NZO mice shared this characteristic with NZB. However, the absolute numbers of cells harvested from NZO mice was quite variable and declined as these mice aged. Evaluation of peritoneal leukocyte subsets in aging NZO males (Table 4) indicated that when such increases in peritoneal cells occurred, it resulted primarily from expansion of the $B$ 
Table 3. Peritoneal Cell Yields (Saline Lavage) in New Zealand Brown (NZB) and New Zealand Obese (NZO) Mice

\begin{tabular}{cccc}
\hline & $\begin{array}{c}\text { Age } \\
\text { (weeks) }\end{array}$ & Weight $(\mathrm{g})$ & Cell Number $\times 10^{6}$ \\
\hline $\begin{array}{c}\text { Females } \\
\text { NZB }\end{array}$ & 28 & $37.3,37.4$ & $14.1,10.0$ \\
NZO & 29 & $41.9,66.1,67.2$ & $28.2,87.2,50.9$ \\
Males & & & \\
NZB & 28 & $46.9,47.6$ & $5.4,5.9$ \\
NZO & 29 & $37.6,43.0,48.5,62.0$ & $17.8,16.1,15.5,25.8$ \\
\hline
\end{tabular}

Values are for individual mice. Note that several NZB male body weights are comparable to those of NZO males in the comparison group.

lymphocyte population and included a high proportion of $\mathrm{B}^{2} 20^{+}, \mathrm{CD}^{+}$(B-1 B) cells. Although there was no difference in total cell number or distribution among $T$ lymphocyte, B lymphocyte, and granulocyte populations distinguishing older diabetic from nondiabetic males, a percentage shift in the diabetic males toward a greater proportion of $\mathrm{B}-2\left(\operatorname{lgM}^{+}, \lg \mathrm{g}^{++}\right)$cells and a lesser proportion of $\mathrm{B}-1 \quad\left(\mathrm{lgM}^{++}, \operatorname{lgD}^{+/}\right)$cells was statistically significant. This shift was also indicated by the moderately lower proportion of $\mathrm{B}^{2} 2 \mathrm{O}^{+}, \mathrm{CD}^{+} \mathrm{B}$ lymphocytes in diabetic mice. However, we have no basis to conclude that these shifts are specifically associated with development of diabetes rather than its consequence.

\section{Hematologic Profiles}

Data shown in Figure 2 and Table 5 provide hematologic comparisons between NZO and the related (and $H 2^{z}$-identical) NZW strain. The results for young NZW females match very well with those posted in the Mouse Phenome Database at The Jackson Laboratory (http://aretha.jax.org/pub-cgi/phenome/mpdcgi?rtn = docs/home). Whereas the NZW strain is characterized by a high white blood cell count, the significantly lower value in the 1.5-month-old NZO mice is at the low end of the normal range. Reciprocally, NZO females exhibited significantly higher red blood cell (RBC) numbers,

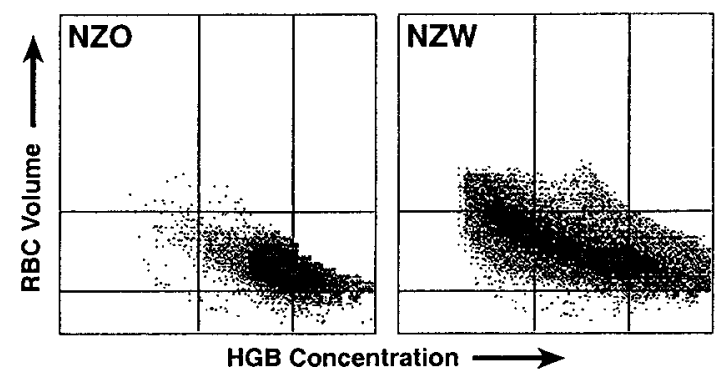

Figure 2.

Red blood cell profiling illustrates the microcytic anemia developing in NZO mice (left panel) compared with the more normal size and hemoglobulin distribution for red blood cell in NZW blood (right panel).

being at the highest end of the range for the inbred strains surveyed in the Mouse Phenome Database. However, these initially high RBC numbers exhibited a significant age-related decline as did reticulocyte numbers in NZO compared with NZW. The comparison of RBC volume to hemoglobin (HGB) concentration for a representative NZO and a NZW female shown in Figure 2 clearly documents the smaller RBC size distribution in NZO. Development of an agedependent microcytic anemia in NZO was indicated by significant declines in other hematologic parameters, including HGB, hematocrit, mean corpuscular volume, mean cell hemoglobin, and mean cell hemoglobin concentration. Serum total bilirubin levels did not differ significantly between NZO and NZW (or NZB) at the 6-month time point, indicating that the anemia was not the consequence of an underlying iron deficiency. Table 6 compares hematologic profiles of NZO males with NZB males. NZB males exhibited an even lower white blood cell count than NZO males. Hemolytic anemia associated with development of Coombs-positive antibodies is a well-known strain characteristic of older NZB mice and is reflected by lower mean cell HGB content and concentration (Ozaki et al, 1983). Although the age-dependent decline in HGB was not as marked in NZO as in NZB mice, the microcytic anemia observed in NZO females (Table 5) was also present in NZO males, as indicated by declines in

Table 4. Phenotypes of Peritoneal Lavage Leukocytes in Nondiabetic (non-db) and Diabetic (db) New Zealand Obese (NZO) Male Mice

\begin{tabular}{|c|c|c|c|c|c|}
\hline & \multirow[b]{2}{*}{ Nucleated cells $\times 10^{6}$} & \multicolumn{4}{|c|}{ Percent of total peritoneal cells } \\
\hline & & $\mathrm{B} 220^{+}$ & $\mathrm{CD}^{+} \mathrm{CD}^{+}$ & $\mathrm{CD}^{+} \mathrm{CD}^{+}$ & Neutrophils \\
\hline NZO non-db & $12.0 \pm 2.1$ & $87.4 \pm 0.9$ & $1.2 \pm 0.4$ & $0.6 \pm 0.1$ & $0.9 \pm 0.3$ \\
\hline NZO db & $9.5 \pm 1.0$ & $83.3 \pm 3.8$ & $2.6 \pm 0.1$ & $0.8 \pm 0.1$ & $0.8 \pm 0.2$ \\
\hline & $\mathrm{CD}^{+}$ & $\lg ^{+} \lg D^{++}$ & $\lg \mathrm{M}^{++} \lg \mathrm{D}^{+/-}$ & & \\
\hline NZO non-db & $63.0 \pm 2.3$ & $49.4 \pm 1.2$ & $47.6 \pm 1.2$ & & \\
\hline NZO db & $56.0 \pm 0.7^{a}$ & $56.5 \pm 2.4^{b}$ & $38.5 \pm 2.4^{c}$ & & \\
\hline
\end{tabular}

NZO/HILt males (4 nondiabetic and 4 diabetic) were 32 to 40 weeks of age.

${ }^{a} p=0.05$.

${ }^{b} p=0.01$

${ }^{c} p=0.04$

Significance of differences between nondiabetics (non- $d b)$ and diabetics $(d b)$ by ANOVA. 
Table 5. Hematologic Comparisons of New Zealand Obese (NZO) with New Zealand White (NZW) Female Mice

\begin{tabular}{|c|c|c|c|c|c|c|c|c|}
\hline Strain & $\begin{array}{c}\text { WBC } \\
{\left[\times 10^{3} / \mu l\right]}\end{array}$ & $\mathrm{RBC}\left[\times 10^{6} / \mu \mathrm{l}\right]$ & RETIC (\%) & $\mathrm{HGB}[\mathrm{g} / \mathrm{dl}]$ & HCT [\%] & MCV [fl] & $\mathrm{MCH}[\mathrm{pg}]$ & $\begin{array}{c}\text { Mean cell HGB } \\
\text { concentration } \\
{[\mathrm{g} / \mathrm{dl}]}\end{array}$ \\
\hline \multicolumn{9}{|l|}{ NZO } \\
\hline $1.5 \mathrm{mo}(n=6)$ & $5.68 \pm 0.49^{a}$ & $10.37 \pm .05^{a}$ & $3.26 \pm 0.09^{a}$ & $15.55 \pm 0.85^{a}$ & $51.15 \pm 0.48^{a}$ & $49.47 \pm 0.27$ & $15.03 \pm 0.11$ & $30.39 \pm 0.35$ \\
\hline $6 \mathrm{mo}(n=3)$ & $7.39 \pm 0.51^{a}$ & $9.76 \pm 0.36^{a b}$ & $1.63 \pm 0.17^{a b}$ & $13.50 \pm 0.51^{a b}$ & $38.83 \pm 1.51^{a b}$ & $39.8 \pm 0.21^{a b}$ & $13.84 \pm 0.29^{a b}$ & $34.77 \pm 0.12^{b}$ \\
\hline \multicolumn{9}{|l|}{ NZW } \\
\hline $1.5 \mathrm{mo}(n=3)$ & $10.74 \pm 0.77$ & $8.16 \pm 0.09$ & $4.5 \pm 0.21$ & $12.13 \pm 0.44$ & $41.70 \pm 0.70$ & $51.13 \pm 0.59$ & $14.88 \pm 0.69$ & $29.13 \pm 1.37$ \\
\hline $6 \mathrm{mo}(n=7)$ & $9.64 \pm 0.41$ & $7.05 \pm 0.56^{b}$ & $4.96 \pm 0.21$ & $10.77 \pm 0.15$ & $37.13 \pm 0.44^{b}$ & $52.64 \pm 0.47$ & $16.55 \pm 0.7$ & $31.49 \pm 1.47$ \\
\hline
\end{tabular}

${ }^{a}$ ANOVA showed a significant interstrain difference $(p<0.05)$ comparing same age females.

${ }^{b}$ ANOVA showed a significant within strain difference $(p<0.05)$ comparing females at different ages.

Data for NZW/LacJ females are consistent with those posted for this strain in the Mouse Phenome Database (http://aretha.jax.org/pub-cgi/phenome/mpdcgi).

Table 6. Hematological Comparisons of New Zealand Obese (NZO) with New Zealand Brown (NZB) Male Mice

\begin{tabular}{|c|c|c|c|c|c|c|c|c|}
\hline Strain & $\begin{array}{c}\text { WBC } \\
{\left[\times 10^{3} / \mu l\right]}\end{array}$ & $\begin{array}{c}\mathrm{RBC} \\
{\left[\times 10^{6} / \mu \mathrm{l}\right]}\end{array}$ & RETIC (\%) & $\mathrm{HGB}[\mathrm{g} / \mathrm{dl}]$ & HCT [\%] & MCV [fl] & $\mathrm{MCH}[\mathrm{pg}]$ & $\begin{array}{c}\text { Mean cell HGB } \\
\text { concentration } \\
{[\mathrm{g} / \mathrm{dl}]}\end{array}$ \\
\hline \multicolumn{9}{|l|}{ NZO } \\
\hline $1.5 \mathrm{mo}(n=5)$ & $5.67 \pm 0.53^{a}$ & $9.75 \pm 0.32$ & $4.18 \pm 0.52$ & $14.58 \pm 0.46$ & $44.84 \pm 3.20$ & $45.84 \pm 2.15$ & $14.96 \pm 0.07$ & $32.90 \pm 1.48$ \\
\hline $6 \mathrm{mo}(n=4)$ & $10.21 \pm 1.93^{a}$ & $9.69 \pm 0.90$ & $2.05 \pm 0.72^{b}$ & $12.93 \pm 1.32$ & $37.10 \pm 4.07$ & $38.03 \pm 0.85^{a b}$ & $13.30 \pm 0.35^{a b}$ & $34.96 \pm 0.72^{a}$ \\
\hline \multicolumn{9}{|l|}{ NZB } \\
\hline $1.5 \mathrm{mo}(n=9)$ & $3.55 \pm 0.26$ & $9.25 \pm 0.18$ & $3.36 \pm 0.30$ & $14.22 \pm 0.37$ & $41.61 \pm 1.10$ & $44.97 \pm 0.50$ & $15.38 \pm 0.14$ & $34.21 \pm 0.19$ \\
\hline $6 \mathrm{mo}(n=2)$ & $3.28 \pm 0.23$ & $8.36 \pm 0.03^{c}$ & $3.80 \pm 0.0$ & $12.35 \pm 0.10^{c}$ & $42.45 \pm 2.15$ & $50.8 \pm 2.70^{c}$ & $14.72 \pm 0.06^{c}$ & $29.06 \pm 1.71^{\circ}$ \\
\hline
\end{tabular}

${ }^{a}$ ANOVA showed a significant interstrain difference $(p<0.05)$ comparing same age NZO vs NZB males.

${ }^{b}$ ANOVA showed a significant within strain difference $(p<0.05)$ comparing NZO males at 1.5 vs 6 months.

${ }^{c}$ ANOVA showed a significant interstrain difference $(p<0.05)$ comparing NZB males at 1.5 vs 6 months.

reticulocyte numbers and significantly lower mean corpuscular volume coupled with reductions in mean cell hemoglobin. As noted above, NŽO mice have previously been reported to produce autoantibodies to native and single-stranded DNA at levels comparable to those observed in $(\mathrm{NZB} \times \mathrm{NZW})$ F1 mice. The present results extend these earlier reports by demonstrating NZB-like hematologic anomalies in NZO mice.

Flow cytometric analysis of $\mathrm{lg}+\mathrm{RBC}$ offers greater sensitivity for the detection of antierythrocyte antibodies in humans than a direct antibody binding (Coombs) test (Wang et al, 2001). An antierythrocyte antibodies positive representative NZB sample histogram is compared with age- and sex-matched NZO and NZB samples in Figure 3. Analyzing 6- to 8-month-old males (NZB, $n=5$; NZO, $n=10$; and NZW, $n=5$ ), we confirmed the presence of antierythrocyte antibodies by flow cytometry in two of five NZB males $(>40 . \%$ $\mathrm{Ig}^{+} \mathrm{RBC}$ ). Only background levels of binding were observed in all NZO males $\left(0.6 \%\right.$ to $\left.2.4 \% \mathrm{Ig}^{+} \mathrm{RBC}\right)$ and only a slightly higher than background binding was noted in NZW males (1.8\% to $8.0 \% \mathrm{Ig}^{+} \mathrm{RBC}$ ).

Comparison of $\mathrm{T}$ and $\mathrm{B}$ lymphocyte subsets in peripheral blood by flow cytometry is shown in Table 7. NZO had the lowest percentage of $\mathrm{CD}^{+} \mathrm{T}$ cells; NZB had an intermediate percentage, and NZW had the highest percentage. Percentages of $\mathrm{CD} 8^{+} \mathrm{T}$ cells were comparable. The high NZW percentage of CD4 ${ }^{+}$ $T$ cells in circulation was offset by a reduced percentage of $\mathrm{CD} 19^{+} \mathrm{B}$ cells.

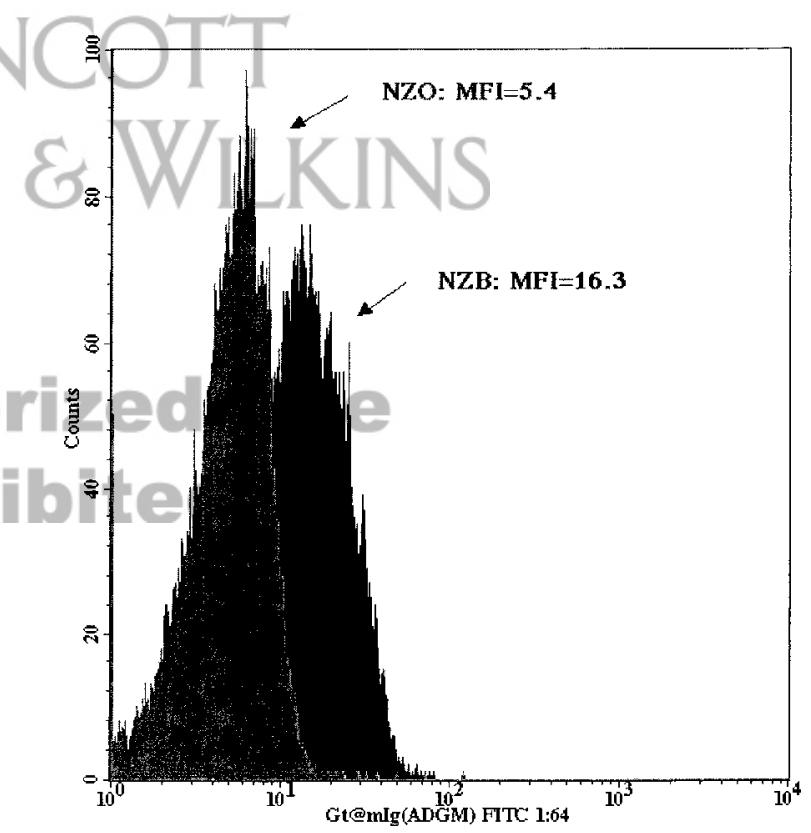

Figure 3.

Representative flow cytometric profile documenting the absence of mouse anti-erythrocyte immunoglobulins in sera from NZO males. Serum from an antibody-positive NZB male is shown for comparison.

\section{Synergism Between NZO/HILt and NZB/BInJ Genomes to} Precipitate Obesity-Induced Diabetes ("Diabesity")

We found previously that the penetrance of diabetes in $\mathrm{NZO} / \mathrm{HI}$ and NZO/HILt males could be increased from 
Table 7. Flow Cytometric Comparison of T and B Cell Subsets in Peripheral Blood of 6-Month-Old NZO, NZB, and NZW Male Mice ${ }^{a}$

\begin{tabular}{cccc}
\hline Strain & \%CD4+ & \%CD8 + & $\%$ CD19+ \\
\hline NZO/HIt $(n=3)$ & $16.05 \pm 2.22^{a}$ & $13.52 \pm 1.76$ & $34.91 \pm 2.67^{a}$ \\
NZB/BInJ $(n=2)$ & $26.12 \pm 3.25^{a}$ & $11.09 \pm 2.17$ & $36.42 \pm 10.76$ \\
NZW/LacJ $(n=3)$ & $43.36 \pm 1.83$ & $16.74 \pm 0.95$ & $15.87 \pm 1.20$ \\
\hline
\end{tabular}

NZO, New Zealand Obese; NZB, New Zealand Brown; NZW, New Zealand White.

a Significantly different from NZW, $p=0.002$ (ANOVA).

$50 \%$ to $90 \%$ to $100 \%$ by intercrossing with the unrelated Swiss-derived NON/Lt strain (Leiter et al, 1998). However, outcross of NZO/HI to SWR, another Swiss-derived strain, suppressed diabetogenesis (Plum et al, 2000). As noted previously, the NZB genome synergizes with the related NZW genome to exacerbate lupus-like symptoms in F1 hybrids (Theofilopoulos and Kono, 1998). Hence, we were curious to see whether the NZB genome would interact comparably with the NZO "diabesity-prone" genome to accelerate or suppress the "diabesity" syndrome. No spontaneous hyperglycemia was observed in NZB/ BINJ mice. Nevertheless, as shown in Figure 4, the genomes of these two strains interacted to promote diabetogenesis in F1 males. Indeed, the NZO $\times$ NZB outcross produced both a more rapid development of
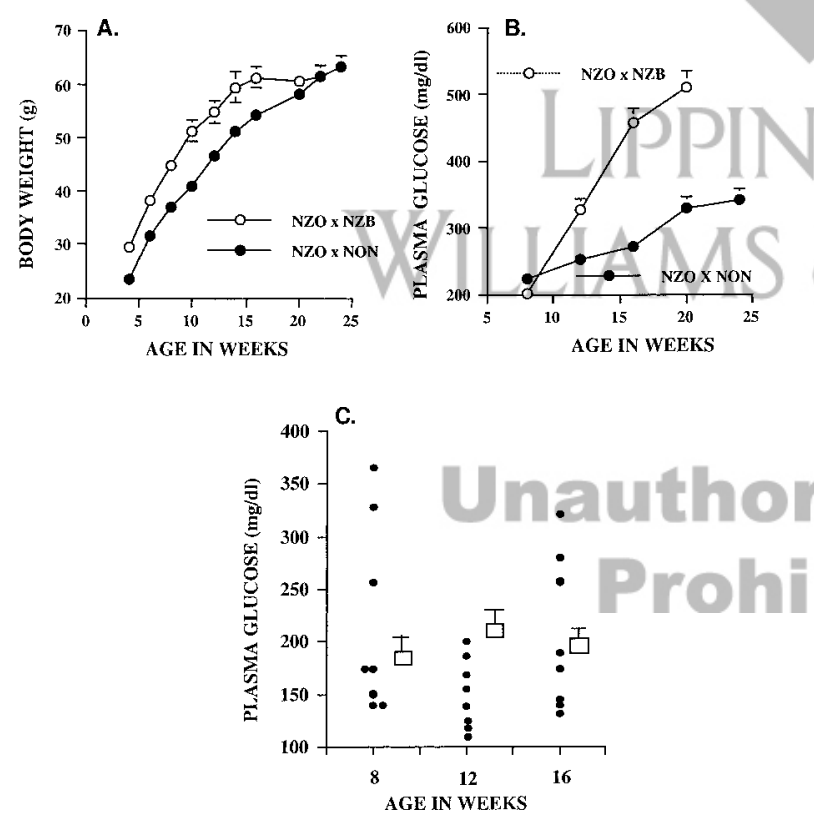

Figure 4.

Synergistic action of NZO/HILt and NZB/BINJ genomes to accelerate "diabesity" in F1 males. A, Earlier development of severe obesity in (NZO $\times$ NZB) F1 males compared with rate of obesity development in the $($ NZO $\times$ NON) outcross, a combination known to exacerbate diabetogenesis. B, Earlier development of severe hyperglycemia in the $($ NZO $\times$ NZB) outcross contrasted to the $($ NZO $\times$ NON) outcross. C, Scattergram showing individual plasma glucose values in a cohort of postpubertal NZO/HILt males. These data illustrate the phenomenon of variable disease penetrance wherein only a subset of NZO/HILt males (filled circles) achieve plasma glucose levels $\geq 250$ $\mathrm{mg} / \mathrm{dl}$ by 16 weeks of age. The boxes show the mean \pm SEM for four B-lymphocyte-deficient NZO. NZB-IgH ${ }^{\text {null }}$ males (N5F2 generation), none of which became stably hyperglycemic over this postpubertal time frame and exhibited normal plasma insulin levels. obesity (Fig. 3A) and hyperglycemia (Fig. 4B) than did the NZO $\times$ NON outcross. Because a stock of NZB mice congenic for a disrupted immunoglobulin heavy chain $(\mathrm{lgH})$ was available (NZB.Igh- ${ }^{\text {tm1Cgn }}$ ) (Taguchi et al, 2001), we assessed the potential contribution of humoral immunity by intercrossing this stock with $\mathrm{NZO}$, and then backcrossing for four generations (N5) to NZO. N5 heterozygotes were then intercrossed and flow cytometry was used to confirm absence of $B$ lymphocytes in peripheral blood leukocytes and spleen in a cohort of four homozygous $\lg ^{\text {null }}$ males. Diabetogenesis in NZO/HILt males has been demonstrated to be a weight gain-dependent threshold phenomenon (Reifsnyder et al, 2000), wherein only $40 \%$ to $50 \%$ of males showing the most rapid weight gain during the peripubertal period transit into chronic hyperglycemia. As shown in Figure 4C, 44\% (4 of 9) of a lgH-intact $\left(\mathrm{lgH}^{+}\right)$control group of $\mathrm{NZO} / \mathrm{HILt}$ males developed hyperglycemia (plasma glucose $\geq 250 \mathrm{mg}$ / dl) by 16 weeks. None of the four B-lymphocytedeficient Ig $\mathrm{H}^{\text {null }}$ males developed chronic diabetes over this age window, despite gaining weight almost as rapidly as $\operatorname{lgH}^{+}$parental controls. However, after 16 weeks, one of these B-lymphocyte-immunodeficient males, although normoglycemic, died suddenly of unknown causes. Histopathologic examination failed to indicate the cause of death; the pancreatic islets contained a high percentage of granulated beta cells in hyperplastic islets. Kidneys of this mouse were free of lesions. Because these immunodeficient males were repetitively bled at monthly intervals to monitor glycemic status, they were maintained in a PIV (pressurized, individually ventilated) air rack to reduce the possibility of infection. Based on the suppression of hyperglycemia out to the 16-week observation point in B-lymphocyte-deficient males, and the finding of normal plasma insulin levels in the surviving three males $(2.4 \pm 0.3 \mathrm{ng} / \mathrm{ml}$ versus $5.6 \pm 2.5 \mathrm{ng} / \mathrm{nl}$ in heterozygous littermates), we conclude that B lymphocytes were potential contributors to the accelerated diabesity observed in (NZO $\times$ NZB) F1 males. However, we cannot exclude that undocumented infections may have altered their metabolic state.

\section{Discussion}

NZO males develop hyperinsulinemia, insulin resistance, glucose intolerance, and are a good animal model for type 2, or noninsulin-dependent, diabetes (Proietto and Larkins, 1993). Although cell-mediated and humoral autoimmunity against beta cells has 
often been described in a monogenic obesity model (Boillot et al, 1986; Serreze et al, 1988; Yoon et al, 1983), such immunophenotypes appear to arise secondarily to beta cell destruction rather than representing the cause of that destruction (Leiter et al, 1987). However, type 2 diabetes in humans and in mice is an extremely heterogeneous genetic disease. The possibility that immune responses against beta cell immunogens may contribute to pathogenesis in obese, insulin-resistant humans genetically predisposed to autoimmunity has recently been reviewed (Wilkin, 2001). Because NZO mice originated from the same outbred stock that gave rise to the autoimmunepredisposed NZB and NZW inbred mouse strains, it is not surprising that NZO mice represent an amalgam of certain immunogenetic and immunophenotypic traits present separately in the latter two strains. Our combined serotypic and genotypic comparison indicates that NZO and NZW are $\mathrm{H}^{2}$-identical. Similar to type 1 diabetes in humans, where MHC heterozygosity for high risk alleles increases disease risk, heterozygous combination of the $\mathrm{H}^{z}$ haplotype of NZW and the $\mathrm{H}^{\mathrm{d}}$ haplotype of NZB has been linked to the murine lupus syndrome developing in F1 hybrids (Fujimura et al, 1998). Thus, an immunophenotype assumed to be $\mathrm{H}^{\mathrm{z}}$-controlled in NZW can now be compared in NZO to establish the extent to which interactions with non-MHC loci are required to produce the phenotype. Genetic outcrosses between NZO and other (unrelated) inbred strains (NON/Lt, SJL/J) have not shown an MHC requirement for "diabesity" (Leiter et al, 1998; Plum et al, 2000). Hence, there is no basis for assuming that there is a primary role for autoimmunity in diabetes pathogenesis in NZO mice as there clearly is in the NOD mouse model for T cell-mediated type 1 diabetes (Serreze and Leiter, 2001). However, "diabesity" developing in NZO/HILt males may entail aspects of what is termed "latent autoimmune diabetes of adults or type 1.5 diabetes" (Pietropaolo et al, 2000). We have used Chinese hamster ovary cells stably transfected with the mouse insulin receptor as target cells to confirm the presence of insulin receptor autoantibodies in NZO/HILt, as originally reported in NZO/ Wehi mice (Harrison and Itin, 1979). In the present report, we demonstrate high frequencies of $B-1 B$ lymphocytes in spleens of NZO mice. As noted by others, B-1 B cells in the spleen coexpressed high slgM with $\mathrm{CD}_{4} 3^{+} \mathrm{CD} 19^{+}$, but a low level of CD23 (Lam and Rajewsky, 1999). This B lymphocyte subset, also present at high frequency in NZB and NZW mice, is associated with autoantibody production by selfreactive B lymphocytes (Hamano et al, 1998; Hayakawa et al, 1984). Normally the B-1 B cells, which have a restricted repertoire of immunoglobulin V-region genes, are believed to be involved in the transition between innate immunity and humoral immunity (Martin and Kearney, 2001). Natural antibodies, primarily of IgM class, represent early defenses against both bacterial and viral infections (Ochsenbein et al, 1999). It has been theorized that natural IgM in conjunction with antigen produces antibody-antigen complexes in the blood that stimulate formation of germinal centers (Boes et al, 1998). In transgenic animals expressing anti-RBC antibodies in the peritoneum, LPS or T-helper 2 cytokines elicited increased autoantibody production by B-1 B cells (Fagarasan et al, 2000). Noncognate help from $\gamma \delta$ T cells induced B lymphocyte migration to lymph nodes where differentiation into plasma cells likely occurred (Fagarasan et al, 2000). We also observed a higher proportion of B-1 $B$ lymphocytes in peritoneal lavages from 8-month-old NZO than from NZB mice with concomitant high titers of IgM in the serum (data not shown). In the accompanying article (Junger et al, 2002), the presence of plasma cells in diabetic NZO islet perivascular infiltrates strengthens the hypothesis that these plasma cells could be B-1 cells that have migrated from peritoneal exudate cells after nonspecific activation, saw islet antigen in pancreatic lymph nodes, and differentiated into autoantibody producing cells. A high but variable number of resident peritoneal cells in NZO mice, resulting primarily from expansion of the $B$ lymphocyte population, and including B-1 B lymphocytes, was not specifically associated with diabetes in NZO males. However, a modest shift in the B lymphocyte subpopulation toward a greater proportion of B-2 cells was noted in diabetic NZO males. This shift might suggest that some disturbance in B cell subset distribution could be associated with diabetes development in NZO males.

Outcrosses between the NZB and NZW strains are known to accelerate autoimmune lupus and kidney disease in their F1 progeny (Theofilopoulos and Kono, 1998). In the present study, we show that NZO and NZB genomes "synergize" in F1 males to accelerate the diabetógenic process. A possible contribution to humoral autoimmunity to this process was indicated by the finding that introduction of a disrupted immunoglobulin heavy chain allele, producing B-lymphocyte-deficient mice, suppressed the diabetogenic process. Interestingly, NZB mice develop peri-insular leukocytic infiltrates (Seemayer and Colle, 1984). This is an immunophenotype shared with NZO, and as shown in the accompanying article (Junger et al, 2002), an unusual feature of the peri-insulitis of $\mathrm{NZO} / \mathrm{HI}$ mice is the presence of a high frequency of $\mathrm{CD} 19^{+} \mathrm{B}$-lymphocytes-surrounding the pancreatic islets, some of which appear to be B-1 B lymphocytes capable of producing autoantibodies. In diabetic males, this peri-insulitic lesion includes plasma cells, a feature not reported in autoimmune $T$ cell-mediated diabetes in either NOD mice or BB rats. Other immune anomalies shared by NZO mice with (NZB $x$ NZW) F1 mice include development of autoantibodies to both native and denatured single-strand DNA, as well as deposition of IgG antibodies on the glomerular basement membrane (Melez et al, 1980, 1985). The progressive microcytic anemia discovered in the NZO/ HILt mouse, with age-associated declines in reticulocytes and red cell size to levels comparable to those observed in NZB mice, indicates that this strain may be developing autoantibodies similar in origin but distinct in function to those developing in NZB mice. 
In conclusion, the present results suggest that NZO mice should be useful to investigators interested in studying the genetic contributions to autoimmunity made by the related NZW and NZB strains. Although the etiopathogenesis of type 2 diabetes in NZO mice is primarily associated with obesity and defects in insulin sensitivity and/or beta cell insulin secretion, the model nevertheless exhibits autoimmune features such as insulin receptor autoantibody production. The preliminary finding that B-lymphocyte-deficient males failed to transit into chronic hyperglycemia suggests that stochastic processes associated with development of humoral immunity might account for the variable male disease penetrance wherein only some of the NZO/HI male mice become overtly diabetic. Continued study of B lymphocyte development and insulin receptor autoantibody production might ascertain differential activators in the disease process, especially in view of the unusual presence of plasma cells in the pancreatic histopathology described in the accompanying article (Junger et al, 2002).

\section{Materials and Methods}

\section{Mice and Phenotype Characterization}

NZO/HILt, NZB/BINJ, NZW/LacJ, and C57BL6 (B6) mice were housed in a specific pathogen-free environment at The Jackson Laboratory. All were fed diet $\mathrm{NIH}-31$ (4\% fat) and received both food and water ad libitum. Male progeny were aged to 24 weeks of age with body weight (BW, g) measured every 2 weeks, plasma glucose measured every 4 weeks (glucose analyzer; Beckman Instruments, Palo Alto, California), and plasma insulin measured by rat insulin radioimmune assay kit (Linco, St. Louis, Missouri). A stock of B-lymphocyte-deficient NZO/HILt mice was produced by congenic transfer of a disrupted immunoglobulin heavy chain $(\mathrm{lgH})$ gene from an 11-generation backcross NZB congenic stock (NZB.lgh- $6^{\text {tm1Cgn }}$ ) (Taguchi et al, 2001). This stock, kindly provided by Dr. L. D. Shultz (The Jackson Laboratory) was intercrossed to $\mathrm{NZO} / \mathrm{HI}$ and then backcrossed four times to NZO before intercrossing to recover homozygotes. Homozygous mutant mice were typed for absence of B lymphocytes by flow cytometry of peripheral blood. Plasma glucose and body weight changes were determined at monthly intervals as described previously (Leiter et al, 1998).

\section{H2 Haplotype Determination}

On importation to The Jackson Laboratory, NZO/HI splenic leukocytes were tested for reactivity to a battery of H2-defined alloantisera by the institution's Genetic Quality Control laboratory using a previously described complement-mediated microcytotoxicity assay (Shiroshi et al, 1981). Because the only positive reactions observed were with antisera against the $\mathrm{H}^{\mathrm{z}}$ haplotype $\left(K^{u} D^{z}\right)$, a CBA/J anti-NZO/HILt-reactive alloantiserum (designated AS-961) was generated as described by Snell (1976) with the modification that only thymus and spleen, but not salivary gland, were used to immunize. This alloantiserum, as expected, gave a positive reaction against $\mathrm{NZO} / \mathrm{HI}$ splenocytes in the microcytotoxicity test. The only other $\mathrm{H} 2 \mathrm{z}$ haplotype-expressing strain at The Jackson Laboratory is the closely related NZW/LacJ strain. Hence, reactivity of AS-961 against NZW/LacJ splenic leukocytes was tested in microcytotoxicity assay to verify $\mathrm{H} 2^{\mathrm{z}}$ haplotype assignment. Molecular analysis of the $\mathrm{H} 2$ locus was performed by (1) PCR analysis of $\mathrm{MHC}$ Class II H2- $A^{z}$ using specific primers described previously (Rozzo et al, 1999) with comparative sizing of the PCR products from NZO, NZW, NZB, and B6; (2) comparative PCR analysis of the MHC class III TNFaproduct generated from specific primers described previously (Fujimura et al, 1998); and (3) PCR product size comparisons using microsatellite-based simple sequence length polymorphisms at D17Mit16, 1cM proximal to the $\mathrm{MHC}$, and the intra-MHC markers D17Mit21, D17Mit103, and D17Mit83 (spanning genetic map positions between $18.64 \mathrm{cM}$ and $18.9 \mathrm{cM}$ ).

Hematology. RBC, white blood cells, and reticulocytes were quantified using an automated analyzer (Advia 120; Bayer, West Haven, Connecticut). The optical cytometry system measured RBC numbers and volumes to produce mean corpuscular volume. Reticulocytes were enumerated by differentially staining RNA with cationic Oxazine 750 dye and measuring at $633 \mathrm{~nm}$ (Shapiro and Stephens, 1986). HGB was determined colorimetrically at $546 \mathrm{~nm}$ after RBC lysis, heme oxidation to the ferric state, and combination with cyanide to produce cyanmethemoglobin (Rice, 1976).

Flow Cytometric Analysis of Leukocyte Subsets. Proportions of various lymphocyte subsets were determined by multicolor flow cytometric analysis on the FACSCalibur cytometer (BD Biosciences, San Jose, California). For peripheral blood analyses, mice were bled via retro-orbital sinus and blood was transferred to buffer containing $0.15 \mathrm{~m} \mathrm{NaCl}$ and $5 \mathrm{~mm}$ EDTA. For flow cytometric analyses of splenic leukocyte populations, mice were killed by $\mathrm{CO}_{2}$ asphyxiation. The spleen from each animal was placed in $\mathrm{Ca}+/ \mathrm{Mg}++-$ free PBS, sieved through nytex mesh bags and a 19-gauge syringe needle was used to produce a single cell suspension. RBC removal for both peripheral blood leukocytes and splenic leukocytes was accomplished by treating samples with 10X Gey's buffer as previously described (Rozzo et al, 1999). All monoclonal antibody $(\mathrm{mAb})$ reagents were obtained from BD PharMingen (San Diego, California). The mAb 1452C11 specific for the CD3 component of the $T$ cell receptor and conjugated to a green fluorescent FITC tag was used to detect $T$ cells. These $T$ cells were then further characterized for CD4 expression using the monoclonal antibody GK1.5 conjugated to the red fluorescent tag Cy3.18-Osu (Cy3; Biological Detection Systems, Pittsburgh, Pennsylvania), or for CD8 expression with the monoclonal antibody 53-6.72 conjugated to a red fluorescent phycoerythrin (PE) tag. A FITC-conjugated $\mathrm{Gr}-1$ specific mAb (RB68C5) was used in combination with a PE conjugated Mac-1specific mAb (M1/70) to delineate macrophages/den- 
dritic cells and granulocytes. Macrophages/dendritic cells stain with the Mac-1 antibody only, whereas granulocytes co-stain with both the Mac-1 and Gr-1 antibodies. CD19 ${ }^{+} \mathrm{B}$ lymphocytes were detected with a FITC-conjugated $\mathrm{mAb}$ (1D3).

Markers chosen for B-1 B cell enumeration were selected according to tissue source as described in the text. To enhance flow cytometric analysis of the B-1 B cell population, samples were analyzed with and without use of a "dump" channel in the Argon red (PI) parameter which permitted exclusion of most non-B cells from the analysis (Baumgarth and Roederer, 2000). A cocktail of biotinylated anti-CD3e/CD4/CD8/Gr-1/F4/80 antibodies was added to the B-1 B cell phenotyping cocktails and counterstained with Red-670 labeled streptavidin. Among the various cocktails used for $\mathrm{B}-1 \mathrm{~B}$ identification were CD43-FITC/slgM-PE/CD19-APC, CD11b-FITC/ CD5-PE/B22O- APC, and IgDa-FITC/CD5-PE B220APC. To enumerate B1-B cells in spleen, a gate was set on PI-negative cells staining with FITC-conjugated CD19 and allophycocyanin (APC)-conjugated IgM (mAb R660.2). This double positive population was analyzed for expression of PE-conjugated CD43 (mAb S7).

Peritoneal lavage cells were collected using $8 \mathrm{ml}$ of $\mathrm{Ca}^{+} / \mathrm{Mg}^{++}$-free phosphate buffered saline. Peritoneal washes were centrifuged, resuspended in 0.5 to $1 \mathrm{ml}$ buffer, and counted using a Coulter counter (Beckman Coulter, Hiahleah, Florida). For flow cytometry, $10^{6}$ cells from each cell suspension were stained with biotinylated B220 mAb (RA3-62B), followed by APCconjugated streptavidin. Parallel samples were stained with a PE-conjugated CD5 mAb (53-7.3) and $\mathrm{PE}-\mathrm{conjugated} \mathrm{Mac}-1$. Propidium iodide labeled the nonviable population. Cells were on ice throughout the staining and analysis, and at $4^{\circ} \mathrm{C}$ during centrifugation. For flow cytometry, aliquots of $10^{6}$ cells were stained as described above to enumerate $T$ cells and granulocytes. B lymphocytes were further characterized using biotinylated anti-B220 followed by Red 670-streptavidin combined with PE-anti-CD5, or, in separate tubes, using biotinylated anti-B220 with PEconjugated anti-IgM and FITC-conjugated anti-IgD $\mathrm{D}^{\mathrm{a}}$. In these studies, forward and side scatter gates that are typical of lymphocytes and myeloid cells were used to exclude debris and dead cells.

\section{Acknowledgements}

The authors are grateful to Drs. Len Shultz, Dave Serreze, Melissa Joliet, Jane Barker, and Luanne Peters of The Jackson Laboratory and Dr. Massimo Pietropaolo for critical reading of the manuscript. The authors also accessed hematologic data generated by the Mouse Heart, Lung, Blood, and Sleep Disorders Center at The Jackson Laboratory (http://www. jax.org/hlbs/documents/strains.html) and deposited in the Mouse Phenome Database (http://aretha.jax.org/ pub-cgi/phenome/mpdcgi?rtn $=$ docs/home).

\section{References}

Baumgarth N and Roederer M (2000). A practical approach to multicolor flow cytometry for immunophenotyping. J Immunol Methods 243:77-97.

Bielchowsky M and Bielschowsky F (1956). The New Zealand strain of obese mice: Their response to stilbestrol and to insulin. Austr J Exp Biol 34:181-198.

Boes M, Esau C, Fischer MB, Schmidt T, Carroll M, and Chen J (1998). Enhanced B-1 cell development, but impaired IgG antibody responses in mice deficient in secreted IgM. J Immunol 160:4776-4787.

Boillot D, Assan R, Dardenne M, Debray Sachs M, and Bach JF (1986). T-lymphopenia and T-cell imbalance in diabetic db/db mice. Diabetes 35:198-203.

Fagarasan S, Watanabe N, and Honjo T (2000). Generation, expansion, migration and activation of mouse B1 cells. Immunol Rev 176:205-215.

Fujimura T, Hirose S, Jiang Y, Kodera S, Ohmuro H, Zhang D, Hamano Y, Ishida H, Furukawa S, and Toshikazu S (1998). Dissection of the effects of tumor necrosis factor-alpha and class II gene polymorphisms within the MHC on murine systemic lupus erythematosus (SLE). Int Immun 10:14671472.

Hamano Y, Hirose S, Ida A, Abe M, Zhang D, Kodera S, Jiang Y, Shirai J, Miura Y, Nishimura H, and Shirai T (1998). Susceptibility alleles for aberrant B-1 cell proliferation involved in spontaneously occurring B-cell chronic lymphocytic leukemia in a model of New Zealand white mice. Blood 92:3772-3779.

Harrison LC and Itin A (1979). A possible mechanism for insulin resistance and hyperglycaemia in NZO mice. Nature 279:334-336.

Hayakawa K and Hardy RR (2000). Development and function of B-1 cells. Curr Opin Immunol 12:346-353.

Hayakawa K, Hardy RR, Honda M, Herzenberg LA, and Steinberg AD (1984). Ly-1 B cells: Functionally distinct lymphocytes that secrete IgM autoantibodies. Proc Natl Acad Sci USA 81:2494-2498.

Herberg L (1988). Insulin resistance in abdominal and subcutaneous obesity: Comparison of C57BL/6J-ob/ob with New Zealand obese mice. In: Shafrir $E$ and Renold AE, editors. Frontiers in diabetes research. Lessons from animal diabetes II. London: Smith-Gordon, 367-373.

Junger E, Herberg L, Jeruschke K, and Leiter EH. (2002) The diabetes-prone NZO/HI strain: II. Pancreatic immunopathology. Lab Invest 82:843-853.

Lam K-P and Rajewsky K (1999). B cell antigen receptor specificity and surface density together determine $B-1$ versus B-2 cell development. J Exp Med 190:471-477.

Leiter EH, Prochazka M, and Shultz LD (1987). Effect of immunodeficiency on diabetogenesis in genetically diabetic $(d b / d b)$ mice. J Immunol 138:3224-3229.

Leiter EH, Reifsnyder PC, Flurkey K, Partke H-J, Junger E, and Herberg $L$ (1998). Non-insulin dependent diabetes genes in mice: Deleterious synergism by both parental genomes contributes to diabetogenic thresholds. Diabetes 47:12871295. 
Martin F and Kearney JF (2001). B1 cells: Similarities and differences with other B cell subsets. Curr Opin Immunol 13:195-201.

Melez KA, Attallah AM, Harrison ET, and Raveche ES (1985). Immune abnormalities in the diabetic New Zealand obese (NZO) mouse: Insulin treatment partially suppresses splenic hyperactivity measured by flow cytometric analysis. Clin Immunol Immunopathol 36:110-119.

Melez KA, Harrison LC, Gilliam JN, and Steinberg AD (1980). Diabetes is associated with autoimmunity in the New Zealand obese (NZO) mouse. Diabetes 29:835-840.

Ochsenbein AF, Fehr T, Lutz C, Suter M, Brombacher F, Hengartner H, and Zinkernagel RM (1999). Control of early viral and bacterial distribution and disease by natural antibodies. Science 286:2156-2159.

Ozaki S, Honda H, Maruyama N, Hirose S, Hamaoki M, Sato H, and Shirai T (1983). Genetic regulation of erythrocyte autoantibody production in New Zealand black mice. Immunogenetics 18:241-254.

Phillips JA, Mehta K, Fernandez C, and Raveche ES (1992). The NZB mouse as a model for chronic lymphocytic leukemia. Cancer Res 52:437-443.

Pietropaolo M, Barinas-Mitchell E, Pietropaolo SL, Kuller LH, and Trucco M (2000). Evidence of islet cell autoimmunity in elderly patients with type 2 diabetes. Diabetes 49:32-38.

Plum L, Kluge R, Giesen K, Altmuller J, Ortlepp JR, and Joost HG (2000). type 2 diabetes-like hyperglycemia in a backcross model of NZO and SJL mice: Characterization of a susceptibility locus on chromosome 4 and its relation with obesity. Diabetes 49:1590-1596.

Proietto J and Larkins RG (1993). A perspective on the New Zealand obese mouse. In: Shafrir E, editor. Lessons from animal diabetes IV. London: Smith-Gordon, 65-73.

Reifsnyder PC, Churchill G, and Leiter EH (2000). Maternal environment and genotype interact to establish diabesity in mice. Genome Res 10:1568-1578.

Rice EW (1976). Erythrocyte and hemoglobin quantitation via a convenient "single-tube" combined nephelometriccyanmethemoglobin manual technic: A reserve system for automated hemoglobinometry. Am J Clin Pathol 66:122-123.

Rozzo SJ, Vyse TJ, David CS, Palmer E, Izui S, and Kotzin BL (1999). Analysis of MHC class II genes in the susceptibility to lupus in New Zealand mice. J Immunol 162:2623-2630.

Seemayer TA and Colle E (1984). Pancreatic cellular infiltrates in autoimmune-prone New Zealand black mice. Diabetologia 26:310-313.
Serreze DV and Leiter EH (2001). Genes and pathways underlying autoimmune diabetes in NOD mice. In: von Herrath M, editor. Molecular pathology of type 1 diabetes. Basel: Karger, 31-67.

Serreze DV, Leiter EH, Kuff EL, Jardieu P, and Ishizaka K (1988). Molecular mimicry between insulin and retroviral antigen p73: Development of cross-reactive autoantibodies in sera of NOD and C57BL/KsJ-db/db mice. Diabetes 37: 351-358.

Shapiro HM and Stephens S (1986). Flow cytometry of DNA content using oxazine 750 or related laser dyes with $633 \mathrm{~nm}$ excitation. Cytometry 7:107-110.

Shiroshi T, Sagai T, and Moriwaki K (1981). A simplified micro-method for microcytotoxicity testing using a flat-type titration plate for the detection of $\mathrm{H} 2$ antigens. Microbiol Immunol 25:1327-1334.

Snell GD (1976). Histocompatibility. New York: Academic Press, 401.

Snell GD, Demant P, and Cherry M (1971). Hemagglutination and cytotoxic studies of $\mathrm{H}-2$. I. H-2.1 and related specificities in the EK crossover regions. Transplantation 11:210-237.

Stall AM, Wells SM, and Lam KP (1996). B-1 cells: Unique origins and functions. Semin Immunol 8:45-59.

Taguchi N, Hashimoto Y, Hsu T, Ansari AA, Shultz L, Dorshkind K, Ikehara S, Naiki M, and Gershwin ME (2001). B cells are selectively associated with thymic cortical but not medullary pathology in NZB mice. J Autoimmun 16:393-400.

Theofilopoulos AN and Kono DH (1998). Mechanisms and genetics of autoimmunity. Ann NY Acad Sci 841:225-235.

Thorburn AW, Holdsworth A, Proietto J, and Morahan G (2000). Differential and genetically separable associations of leptin with obesity-related traits. Int J Obes 24:742-750.

Wang Z, Shi J, Zhou Y, and Ruan C (2001). Detection of red blood cell-bound immunoglobulin $\mathrm{G}$ by flow cytometry and its application in the diagnosis of autoimmune hemolytic anemia. Int J Hematol 73:188-193.

Wanstrat A and Wakeland $E$ (2001). The genetics of complex autoimmune diseases: Non-MHC susceptibility genes. Nat Immun 2:802-809.

Wilkin TJ (2001). The accelerator hypothesis: Weight gain as the missing link between type I and type II diabetes. Diabetologia 44:914-922.

Yoon J-W, Melez KA, Smathers PA, Archer JA, and Steinberg AD (1983). Virus-diabetes induced in New Zealand autoimmune mice. Diabetes 32:755-759. 